\title{
OS DESAFIOS DA SALA DE RECURSOS COMO FERRAMENTA COMPLEMENTAR Å INCLUSÃO DE ALUNOS COM NECESSIDADES EDUCACIONAIS ESPECIAIS NO ENSINO REGULAR ${ }^{*}$
}

\author{
Gilmara Ferreira Alvim ${ }^{1}$ \\ Adriana Gomes Calixto César ${ }^{2}$
}

\section{INTRODUÇÃO}

Salas de recursos são espaços escolares da rede pública estadual ou municipal destinados ao atendimento de estudantes com necessidades educacionais especiais. Nestes espaços são encontrados materiais lúdicos que devem suplementar e complementar a escolarização, sendo as atividades oferecidas por profissionais qualificados no contra-turno do colégio em que o aluno está matriculado.

De acordo com PASIAN, MENDES e CIA (2014, apud BRASIL, 2007), o programa da sala de recursos foi criado na intenção de promover o ensino com qualidade para alunos com deficiência, transtornos globais do desenvolvimento e altas habilidades - sendo este, o público alvo da educação especial. As salas de recursos devem, portanto, oferecer subsídios para que os estudantes portadores de necessidades educacionais especiais possam participar e interagir, considerando suas limitações e adaptações, com os outros estudantes em suas respectivas classes no ensino regular.

\footnotetext{
*DOI - 10.29388/978-65-86678-08-6-0-f.21-26

${ }^{1}$ Professora Ma. de Ciências e Biologia da Rede Estadual/SEEDUC-RJ,

E-mail: gilmara.bio@gmail.com

${ }^{2}$ Professora da Sala de Recursos na Rede Estadual/SEEDUC-RJ,

E-mail: dricalixto.cesar@gmail.com
} 
Estes espaços educativos trabalham com pequenos grupos de alunos, sendo que cada estudante possui suas individualidades e necessidades, sendo estas diagnosticadas por meio de laudo médico ou observadas no cotidiano da sala de aula pelos professores regentes das turmas, sendo assim, as salas de recursos trabalham de forma paralela ao ensino regular, auxiliando o desenvolvimento cognitivo dos estudantes. Porém, são muitos os desafios enfrentados pelas salas de recursos, estando entre eles o planejamento específico para cada caso, a busca por materiais didático-pedagógicos específicos e adequados; diagnósticos precisos de alguns estudantes para a eficácia do acompanhamento e a própria estagnação de alguns discentes em seu processo de aprendizagem. Além disso, os professores regentes das turmas regulares devem estar capacitados para receber e atender estes alunos, incluindo-os verdadeiramente no processo escolar, contribuindo para seu aprendizado.

A partir do exposto, este trabalho visa relatar, por meio de uma análise qualitativa, o acompanhamento dos estudantes usuários da sala de recursos de um colégio público estadual localizado na região centro sul fluminense, no município de Barra do Piraí, de forma a revelar os desafios enfrentados tanto pela professora responsável quanto pelos próprios estudantes, que tentam superar suas dificuldades e atingir degraus mais altos em seu processo de aprendizagem.

\section{METODOLOGIA}

Para a organização deste escopo, foi realizado um levantamento com a professora responsável pela sala de recursos do colégio em questão a fim de averiguar quantos estudantes estavam sendo atendidos na respectiva unidade, no ano de 2018. Foram relacionados 26 estudantes com escolaridades que variam do Ensino Fundamental II ( $6^{\circ}$, $7^{\circ}$ e $8^{\circ}$ anos), Ensino Médio ( $1^{\circ}$ ano) e Educação de Jovens e Adultos (módulos II e III), nos três turnos de funcionamento do colégio. Dos estudantes atendidos, somente 15 possuem laudo médio, diagnostica- 
dos como deficientes intelectuais; os outros 11 discentes, mesmo não possuindo encaminhamento médico, foram observados na rotina escolar pelos professores regentes e então encaminhados para uma avaliação e posterior atendimento especializado, comprovadas suas dificuldades de aprendizagem. A análise em questão levou em consideração todo o período letivo de 2018 e fez um levantamento dos relatórios bimestrais preenchidos pelos professores de diversas disciplinas, que atendem estes alunos em suas classes de ensino regular.

\section{RESULTADOS E DISCUSSÃO}

De acordo com PASIAN, MENDES e CIA (2014), é tendência das salas de recurso o atendimento especializado de maneira diversificada, porém com ênfase na escolarização do aluno à classe comum. Para WEBER e BENETTI (2012), o professor deve estar sempre atento às fases de desenvolvimento dos estudantes, sendo um facilitador no seu processo de aprendizagem, tentando sempre buscar ferramentas de auxílio que corroborem com este processo. As autoras afirmam ainda que as dificuldades de aprendizagem muitas vezes se manifestam agregadas a sentimentos como revolta e tristeza, além de comportamentos de isolamento, ansiedade e agressividade, sendo, portanto, de fundamental importância a observação do professor regente e seu olhar cauteloso e crítico para cada caso apresentado.

A análise realizada neste trabalho se deu tanto pelo acompanhamento direto dos estudantes pela sala de recursos, quanto pelos relatórios bimestrais preenchidos pelos professores das turmas regulares da referida unidade e revelou que mesmo diante das diversas estratégias de ensino e materiais lúdicos de apoio, os estudantes, em sua maioria, continuam apresentando muitas dificuldades em desenvolver leituras plenas e compreender textos diversos; persiste a insuficiência em ordenação de ideias e compreensão de sequências lógicas, dificuldades de retenção de conteúdos e na execução de operações básicas de matemática. 
É importante ressaltar que os estudantes atendidos apresentam dificuldades próprias, que, em algumas vezes, não se somam, por exemplo, determinado aluno que apresenta dificuldade de leitura e interpretação de textos, pode ter um melhor desempenho em operações matemáticas. Entretanto, mesmo diante das estratégias diversificadas e complementares de ensino e os materiais de apoio (Figuras 1, 2, e 3), há pouca ou nenhuma (alguns casos) evolução da autonomia de aprendizagem dos estudantes em relação ao seu quadro inicial.

Figura 1. Materiais de apoio da sala de recursos da referida unidade escolar: reconhecendo palavras, sílabas e números (CÉSAR, 2018).

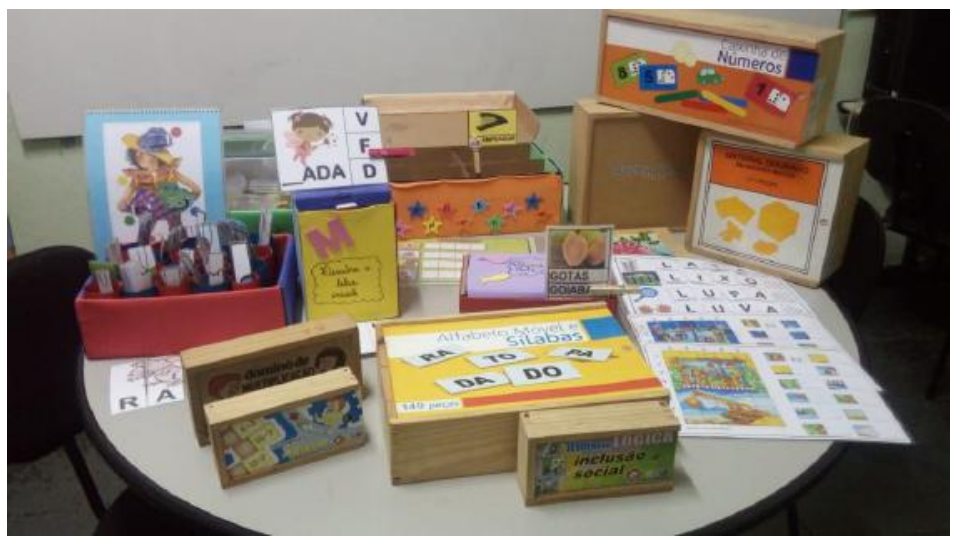

Figura 2. Materiais de apoio da sala de recursos da referida unidade escolar: palavras, ordenação e sequência lógica (CÉSAR, 2018).

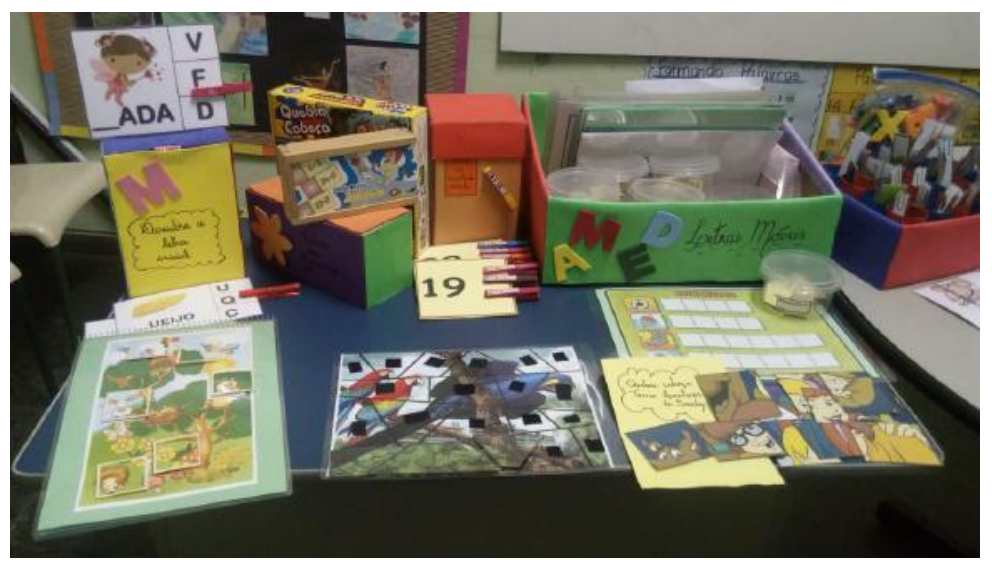


Figura 3. Materiais de apoio da sala de recursos da referida unidade escolar: figuras geométricas, quebra-cabeça, palavras e sílabas (CÉSAR, 2018).

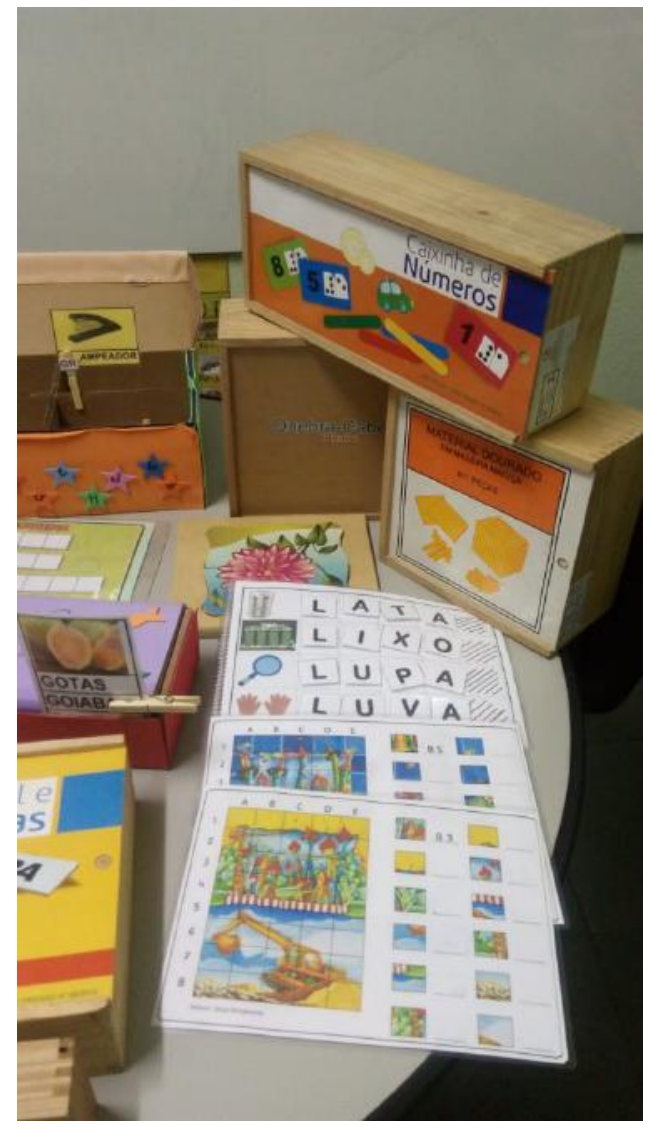

\section{CONSIDERAÇÕES FINAIS}

O ambiente pedagógico deve ser dinâmico e de interação, capaz de estimular os estudantes nas tarefas escolares e na busca pelo conhecimento. Esta característica se aplica, inclusive, à educação especial e inclusiva, que deve promover meios para inserir os estudantes no processo de aprendizagem de maneira eficaz e significativa.

As dificuldades apresentadas pelos estudantes atendidos pela sala de recursos tornam-se um grande desafio para a unidade escolar, que busca inserir tais discentes nas classes de ensino regular, garan- 
tindo-lhes uma educação inclusiva e de qualidade. A existência de uma grande demanda de planejamento e organização das ações, a constante busca por metodologias, estratégias e materiais que se encaixem no perfil dos alunos, que muitas vezes são confeccionados pela própria sala de recursos, além do esforço pedagógico e afetivo que a situação exprime são elementos coexistentes com as dificuldades dos estudantes, mas mesmo diante dos inúmeros desafios enfrentados diariamente para garantir a esta clientela especial uma aprendizagem significativa, a sala de recursos da unidade em questão realiza seu trabalho de maneira afetuosa e comprometida, através de atividades lúdicas e materiais concretos, buscando oferecer um aprendizado que valorize suas próprias experiências, contribuindo para sua inclusão escolar e social.

\section{REFERÊNCIAS}

PASIAN, Mara Silvia; MENDES, Enicéia Gonçalves; CIA, Fabiana. Sala de recursos multifuncionais: revisão de artigos científicos. Revista Eletrônica de Educação, v. 8, n. 3, p. 213-225. 2014.

WEBER, Vera Lucia da Silva; BENETTI, Luciana Borba. A eficiência das salas de recurso para alunos com deficiência de aprendizagem no município de São Gabriel - RS. Revista Monografias Ambientais, v. 8, n. 8, p. 1900-1915. 2012. 